\title{
An overview on vehicle dynamics
}

\author{
Shaopu Yang • Yongjie Lu $\cdot$ Shaohua Li
}

Received: 29 September 2013 / Revised: 5 October 2013 / Accepted: 9 October 2013 / Published online: 29 October 2013

(C) Springer-Verlag Berlin Heidelberg 2013

\begin{abstract}
As a basic theory of the vehicle industry, the vehicle dynamics plays an important role in the development of the vehicle industry. In the past decades, great progress was made in the theory and experiment of vehicle dynamics. This article summarizes recent advances in vehicle dynamics. In vehicle dynamics, the vehicle body (sprung mass), the suspension component (spring and damper) and tire (unsprung mass) are essential parts of the system. The modeling approaches and characteristics of the vehicle, tire and driver model with the respect to handling and driving dynamics are summarized in the paper. The important research issues about the vehicle-pavement coupled dynamics are discussed in detail. Several problems and directions for the further studying in vehicle dynamics are pointed out.
\end{abstract}

Keywords Vehicle dynamics - System modeling . Vehicle-pavement coupled dynamics · Overview

\section{Introduction}

The global vehicle industry and market structure experienced an unprecedented scale of change in the 1990s. There has been an increasing demand on vehicle safety, environmental protection and intelligent control. Thus, the advanced technologies such as computer technology, virtual reality

S. Yang $(\bowtie) \cdot$ S. Li

School of Mechanical Engineering, Shijiazhuang Tiedao

University, Shijiazhuang 050043, Hebei, China

e-mail: yangsp@stdu.edu.cn

Y. Lu (ه)

Key Laboratory of Traffic Safety and Control in Hebei,

Shijiazhuang 050043, China

e-mail: lu-yongjie@163.com technology and intelligent algorithm have been widely used in the vehicle industry. The vehicle dynamics plays an important role in the development of vehicle industry. The early research of vehicle dynamics concentrated on various working conditions and service performances under external excitation [1]. In the 1930s, researchers began to focus on the steering, suspension mechanics and driving stability. Lanchester Maurice and Segel studied the effects of the external environment (such as road surface roughness, air flow, tire and driver) on the vehicle dynamics and the coupling interaction of these conditions [2]. In 1993 Segel [3] presented a comprehensive summary on the achievements of the vehicle dynamics before 1990 in the Proceedings of Institution of Mechanical Engineers. In the following decades, the vehicle ride comfort and handing stability research have been widely investigated. The handling dynamics deals with the lateral dynamics or transverse dynamics of the vehicle, which mainly refer to vehicle handling stability, vehicle sideslip caused by tire lateral force, yawing and roll motion. The handing stability of vehicle dynamics research went through the development from experimental studies to the theoretical analysis, from the open-loop to the closed-loop. The representative monographs of vehicle handling dynamics include "Vehicle Handling Dynamics Theory and Application" by Abe [4], "Vehicle Handling Dynamics Theory" written by Guo [5]. The vehicle driving dynamics is divided into longitudinal dynamics and vertical dynamics, which includes driving, braking and ride comfort. The problem of driving slip and braking slip are solved by the study of vehicle longitudinal tire force, which can also improve driving and braking efficiency. The ride comfort focuses on vehicle vibration and pitch movement caused by vertical tire force. The representative monographs are "Vehicle Dynamics and Control" written by Rajamani [6], "Vehicle Dynamics Theory and Applications" written by Zhang [7]. In addition, the field of vehicle 
dynamics research also involves the longitudinal force of tire when vehicles are speeding up or braking and vehicle vibration caused by the working engine, etc.

In vehicle dynamics, the vehicle body (sprung mass), the suspension component (spring and damper) and tire (unsprung mass) are essential parts of the system. The vehicle-road coupling is another important aspect of vehicle dynamics. In this paper, the vehicle system (full vehicle, tire, driver) modeling methods are reviewed. The important research issue about the vehicle-pavement coupled dynamics is discussed. Finally, several outstanding problems and the future development trend of vehicle dynamics are proposed.

\section{Research progress of vehicle dynamics model}

\subsection{Vehicle dynamics model}

The vehicle dynamics models went through the development from the traditional lumped parameter model to the finite element model (FEM), the dynamical substructure model and the multi-body system dynamics model, from the linear model to the non-linear model with the non-linear stiffness and the non-linear damping.

\subsubsection{Lumped parameter model}

For the lumped parameter modeling method, the finite degree of freedom (DOF) model of a vehicle system is comprised of mass, spring and damper elements. The examples include a quarter vehicle model with $2 \mathrm{DOF}$, half vehicle model with four or five DOF, full vehicle model with 7 or $18 \mathrm{DOF}$, etc.

For the vehicle handling stability research, the number of DOF can be two, ten or more such as 2 DOF (lateral, yaw), 3 DOF (longitudinal, lateral, yaw) and 4 DOF (longitudinal, lateral, yaw, roll). It is known that a 2 DOF vehicle model is usually applied when the vehicle lateral acceleration is less than $0.3 \mathrm{~g}[8,9]$, as shown in Fig. 1. If the tire cornering properties is in the linear range, the vehicle model can be simplified as a 3 DOF model with lateral, longitudinal and yaw movement. The model is also widely used to study vehicle handling dynamics while the vehicle encounters emergency collision avoidance $[10,11]$. Liu proposed a four-wheel-steering vehicle nonlinear lateral dynamics model of 3 DOF based on Pacejka model. The experimental study and simulation analysis for the vehicle single lane change, double lane change are also complete [12]. Huh proposed a six-axis heavy vehicle model of 18 DOF with MATLAB/Simulink, in which the suspension and tires characteristics are nonlinear. It is found that the effects of middle steering axle on the yawing angular velocity and lateral acceleration cannot be ignored [13]. The simulation
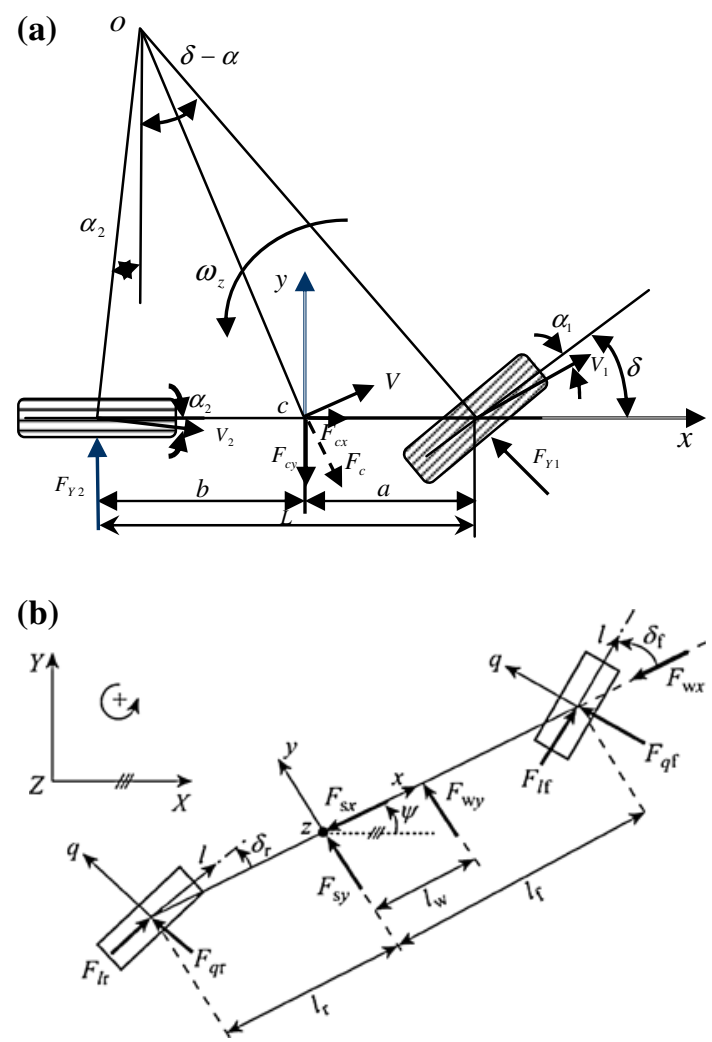

Fig. 1 Lumped mass model of vehicle handling dynamics. a 2DOF (lateral, yaw) model [8,9], b $3 \mathrm{DOF}$ (longitudinal, lateral, yaw) model [12]

research of handling stability went through the development from the simulation of the steady state response characteristics to the simulation of transient response characteristics and cornering braking characteristics. Based on 250 references, Vlk [14] summed up the truck handling stability during longitudinal traveling, lateral traveling and braking. Nagai et al. [15] put forward an active control model to control the front wheel steering angle, which can improve the vehicle dynamic performances under the condition of steering, braking, changing lane and wind disturbance. Zhao et al. [16] reviewed the development history of vehicle dynamics and the main research methods. Examples of vehicle handling dynamics and inverse dynamics are given.

For the vehicle driving dynamics, there is a quarter vehicle model of 2 DOF, which assumes the movement of the vehicle front axle and rear axle to vibrate independently. The simplest quarter vehicle model is one-dimensional model. It is widely applied in the research and design of the vehicle active and semi-active suspensions [17-19]. The lumped mass vehicle model of 7,8 , or more DOF is usually three-dimensional, which can analyze vertical, pitch and roll vibrations of the vehicle $[20,21]$. Cebon proposed a three-dimensional vehicle model with 14 DOF considering the longitudinal tire force, lateral tire force and the non-linear suspension [22]. 
(a)

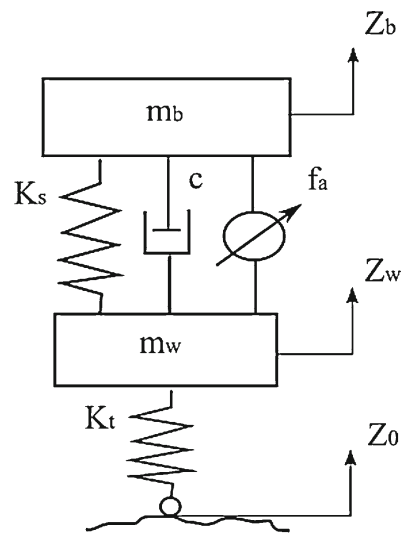

(b)

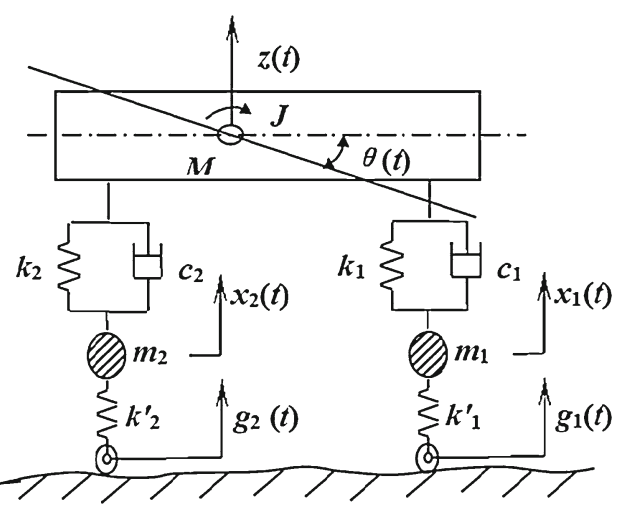

(c)

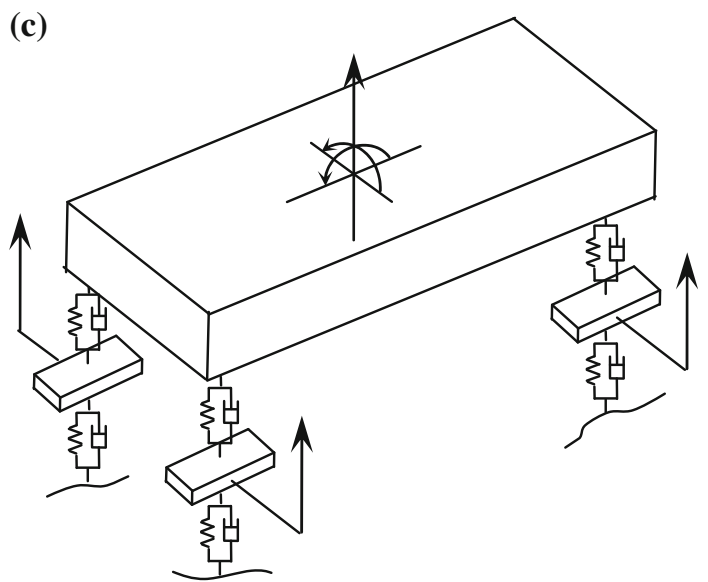

Fig. 2 Lumped mass model for vehicle driving dynamics. a Onedimensional (quarter vehicle) model [19], b Two-dimensional (4 DOF) model [23,24], c Three-dimensional (7 DOF) full vehicle model [20,21]

Several typical vehicle models for the driving dynamics are shown in Fig. 2.

Although these lumped mass models are simplifications of the actual vehicle structure, they can capture the vehicle vibration characteristics and the effects of structural parameters from the vehicle performance. The advantage of these models lies in their simplicity and the possibility to obtain analytic descriptions and to design active or semi-active controls.

\subsubsection{Virtual prototyping model}

The finite element (FE) modeling demands much more calculation time. The FE vehicle model is mainly used for the dynamic design of complex parts such as vehicle body, engine mount, etc. [25,26]. The dynamical substructure approach includes the mechanical admittance method and the modal synthesis method. The modal synthesis method has been successfully applied to study the vehicle vibration noise mechanism and vibration transfer characteristics of the vehicle chassis and frame [27]. At present, the dynamical analysis modeling of the vehicle is usually combined with the lumped mass method, FE method and modal synthesis method.

With the development of computer technology and application software, the functional virtual prototyping (FVP) technology makes more and more complex models of the vehicle [28]. The core contents of the FVP are the MultiBody System Kinematics and Dynamics modeling theory. In recent years, some scholars begin to build the vehicle model and analyze its dynamic behavior by using the FVP software. The representative multi-body dynamics software includes Simpack, ADAMS and TruckSim. Valášek et al. [29] established a virtual prototype of triaxial heavy vehicle model in Simpack software and designed the semi-active controller in MATLAB/Simulink. Hou et al. [30] and Ieluzzi et al. [31] developed a vehicle model in ADAMS/CAR and studied the semi-active suspension effectiveness for improving the vehicle vibration performance. Odhams developed a complex multi-body model of heavy load hinged vehicle using TruckSim software and studied the driving safety of trailer vehicle under the operation of active steering system [32]. Ren et al. [33], Yang et al. [34] and Lu et al. [35] investigated the dynamic behavior such as vehicle ride comfort, handling stability and so on, using ADAMS software. The most significant advantage of the multi-body vehicle model is the parametric modeling. In order to make it clear which vehicle parameter (vehicle geometric position, suspension stiffness and damping characteristics) has the most important effect on the vehicle performance, several trial simulations of the vehicle must be done. The traditional computational optimization approach becomes inadequate in dealing with the complex multi-body model of the vehicle with a lot non-linear parameters. A discrete optimization method proposed by Fisher [36], known as the design of experiment (DOE) for the optimization, has been adopted to study the vehicle design. This method has been widely used in the detection, earthquake prediction and product design due to its effectiveness, robustness, and high-quality solutions [37,38]. 
Lu presented an orthogonal optimization program for a multibody vehicle model. After several virtual experiments and range analysis, the most important influencing factor and its range are screened out. Then a matching scheme of vehicle parameters is proposed to achieve the ride comfort and the road friendliness optimization [39].

Although the lumped mass models of a vehicle can be used for the vehicle performance analysis and control study, they are too simple to show the nonlinear behavior of the suspension system and describe the detail of the vehicle structure. The virtual prototyping model (FE or multi-body) has advantages such as user-oriented interactive environment and virtual prototyping pretreatment function, which are important to the development of vehicle dynamics.

\subsection{Tire model}

The tire is the link between a vehicle and the road surface. It does not only support the vehicle load, but also attenuates the shock from the uneven road surface. Thus, the tire dynamics plays an important role in the vehicle performance.

\subsubsection{Tire mechanical model}

The research about the vehicle tire mechanics originates from the aero tire research, which is dated back to the early 1930s. The tire mechanical model can be divided into three categories: pure physical model, empirical model and semiempirical model [40].

According to the tire physical structure and working mechanism, the pure physical model is proposed in the form of mathematical expression to describe a tire mechanical characteristic. The pure physical models include Fiala, Gim and Dugoff tire model, etc. In the Fiala model [41], the belt and the buffer layers of a tire are simplified to an elastic beam under the lateral concentrated force. The tire lateral force and aligning torque is described by the dimensionless expressions. Although the calculation error of the Fiala model aligning torque is large, the cornering force has a better accuracy within $5^{\circ}$ slip angle, as shown in Fig. 3a. The Gim model $[42,43]$ is based on the Bergman 3D spring model, in which the tire side slipping and longitudinal sliding is governed by a kinetic equation of the infinitesimal element between the tire and road surface. It is widely used in the field of vehicle dynamics simulation and control study [44]. The Dugoff model expresses the friction factor between the tire and the road as a function of the friction reduction factor and the friction when both the tread sliding speed and vehicle sliding velocity are zero. This gives a relationship between the tire-road surface friction coefficient and the cornering or longitudinal force in the Dugoff model [45]. The tire can have

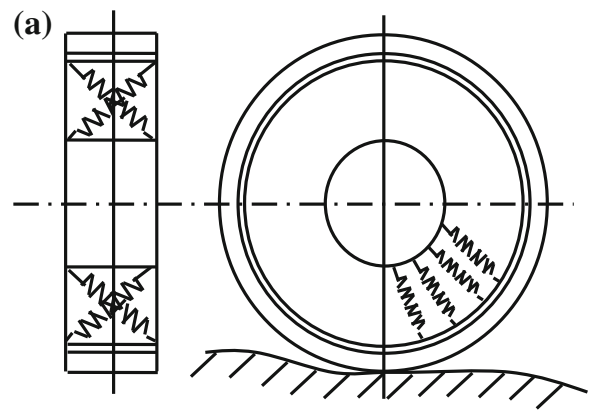

(b)

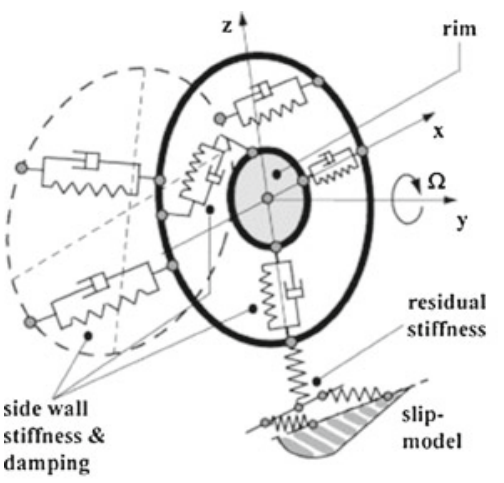

(c)

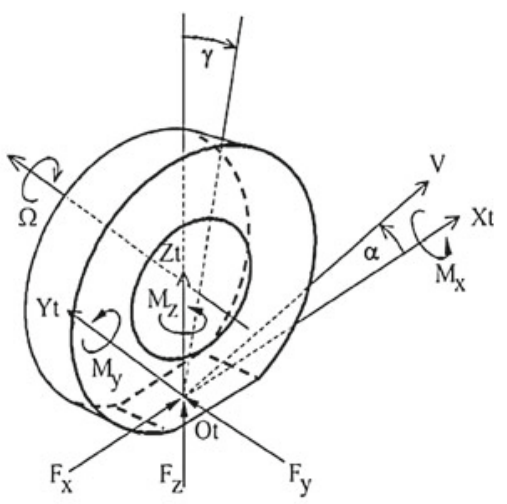

(d)

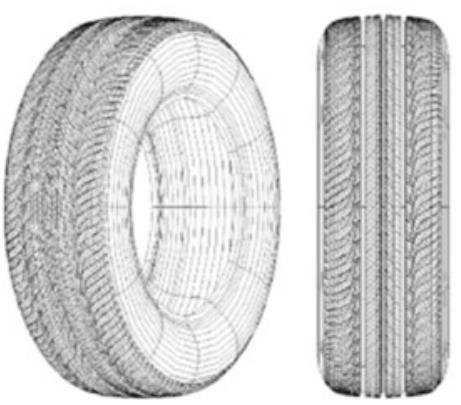

Fig. 3 Tire models. a Physical model (Fiala [41]), b Semi-empirical model (Swift) [52], c Semi-empirical model (UniTire) [5,47], d FE model [51] 
large deformation under the loading, which is difficult to be described analytically. Therefore the pure physical model can only serve as the basis for the semi-empirical model.

From experimental data of tire, an empirical model can be directly built. The semi-empirical model has higher precision combined with the theoretical model and the experimental data. The famous Magic Formula model is proposed by Pacejka [40] based on extensive experiments. It is a semiempirical and semi-theoretical model, which is based on the tire physical prototype and the experimental data. It can be used to describe the six-directional wheel force in the steady state. In order to extend the frequency range of the tire, Pacekja introduced a dynamical rigid ring model based on the Magic Formula model and proposed a Swift model, as shown in Fig. 3b. The Magic Formula and Swift tire models were developed at Delft University of Technology. They were implemented in the commercial software (ADAMS, SIMPACK and MATLAB/Simulink), and named as MF-Tyre and MF-Swift, respectively. The mathematical expression of the tire lateral and longitudinal instantaneous deformation under any movement is calculated by Guo and $\mathrm{Lu}$ [46] with a theoretical tire model in non-steady state. The calculation error of a pure theoretical model caused by unavoidable simplification can be compensated by the experiment and the data fitting in a semi-empirical model. Guo et al. [47] also put forward a semi-empirical model called UniTire Model that can describe a tire mechanical characteristics in an E exponential form. It describes the six-component characteristics of a tire in a variety of working conditions, and has high precision simulation for the complex and extreme conditions.

The FE model of the tire has experienced from the static and dynamic analysis to the thermal coupling, abrasion, fatigue life prediction and vehicle-tire- pavement coupled analysis. Narasimha used the ABAQUS software to investigate the lateral and longitudinal forces of pneumatic tires during steering and braking [48]. Gall and Tkacik [49] built a 3D FE model of tire with the tread, and found out that the normal stress reaches the maximum value when the friction coefficient is in the vicinity of 0.55 . The distribution of normal stress tends to be stable with the increasing of friction coefficient. It is suited for the analysis of transient rolling contact, internal stress, modality, noise and so on [50,51]. However, there are still limitations for the FE method. For example, the quantitative relationship between variable parameters cannot be expressed explicitly. Several typical tire models are shown in Fig. 3.

\subsubsection{The contact between tire and road}

The relationship between the tire model and the road surface are usually assumed as the point contact. It is the convenient model for the dynamic analysis and widely used in the theoretical study of vehicle dynamics [53]. Kyongsu estab- lished the road-surface roughness by using six sinusoidal waves and calculated the tire force by using the point contact model. The simulation result of the point contact tire model is rather similar to the measured tire force [54]. Collins [55] believed that the point contact model is adequate for the use in the shimmy analysis of the tire yaw and structuraltorsion shimmy modes of vibration. Arunas and Jonas [56] compared the results of the point-contact model, the flexible ring model and the flexible band model based on the quarter vehicle model. Costanzi and Cebon [57] also used the point-contact tire model to calculate the tire dynamical force and the road deformation, which were validated by field data.

However, the point contact model is only appropriate for the vertical loading condition, in which the range of road surface excitation frequency is between 0.1 and $0.2 \mathrm{~Hz}$. When the pavement wavelength is greater than $3 \mathrm{~m}$, the model cannot reflect the motions of shortwave (high frequency) excitations [58]. The high-frequency filtering property of a tire is called the enveloping characteristics, which is initially studied by Lippmann et al. [59]. The enveloping characteristics means that a tire has a property to envelope the road profile irregularities and attenuate the high spatial frequency components. Other tire models include line contact model or surface contact model. The spring and damping elements along with the imprinting length are used to form a fixed imprinting tire model. The imprinting length is invariant and the confluence of the tire force is always in the direction of the wheel center, which also has an enveloping characteristic within the imprinting. With this model, the calculated value of vertical axle load under the high frequency excitation is lower than the actual value [60]. Guo et al. [61-63] presented a flexible roller contact tire model and carried out simulations of a vehicle vibration system based on the rigid and the flexible roller contact tire model. Guan and Dong [64] put forward a vehicle system model with an enveloping tire model to study the vehicle active suspension performances. The vehicle load distribution on the road surface is assumed to be uniform and symmetrical with parabolic or trapezoidal distribution [65]. The true distribution of the loading on local contact area on a moving vehicle is not symmetrical. A non-uniform distribution model is introduced by Guo [66]. A modified elastic roller tire model is proposed by Yang et al. [67]. A twodimensional vehicle-road-subgrade coupling system based on the modified tire model is developed. The improved elastic roller line contact model and point contact model of the vehicle-road coupling system are compared.

There has been research work on experimental modeling of a tire. The South Africa researchers of Council for Scientific and Industrial Research (CSIR) developed a vehicle-road surface pressure transducer array (VRSPTA), commonly known as the "3-D Stress Sensor" [68-70]. Groenendik et al. [71] and Ronald [72] proposed the simplified mathematical 
formula of the tire contact stress distribution based on the tire test results of freely rolling tire. A measurement device was developed and used to measure the tire ground pressure distribution of light vehicles with different tread patterns in different conditions of the tire inflation pressure and axle loading [73,74]. A rig was developed for the tire impact test, allowing a drop mass with a round indenter to hit the pressurized tires with different impact energies [75]. Although the cost of the test is relatively high, it provides important input to the mathematical tire model and analysis of physical properties.

\subsection{Driver model}

A number of models have been developed to describe the human driving behavior and evaluate the vehicle safety in braking and turning. An early driver model based on the cognitive model was established in 1938 by Gibson and Crooks [76]. In the 1980s, the number of publications about the driver model had reached a peak. McRuer [77] is one of the scholars who has a great influence on the driver model of control theory. A long article written by MacAdam [78] expounded the driver's limited driving ability in detail. Driver's behavior is not only limited to the control of extremities and the brain, but also related to the interaction with the outside world. It is a very complex process of perceiving location and speed as well as the action time, which involves the work of different parts of the brain (identification of position, decision-making, action to complete the task). Kinecke and Nielsen [79] summarized the driver's behavior characteristics from the point of view of dynamics and control. Driver's behavior is nonlinear, time varying, adaptive and random. Furthermore, driver's response has the property of foresight and hysteresis. The foresight is manifested as predicting the development of traffic situation and preventing or handling in advance. Hysteresis shows up as delay in response to the events. Ranney puts forward several cognitive models of driving behavior. But, the model parameters are hard to be obtained [80]. Cacciabue [81] summarized the various factors that contribute to modelling human behaviour in the specialized environment. Baron et al. [82] studied an optimal driver control. Torsten and von Stryk [83] proposed a control system combining the driver and vehicle factors in the optimal control theory. The driver's transient choice of path and speed has an influence on the vehicle model directly. But this factor did not include driver's motivation and personal characteristics. Cheng and Fujioka [84] used the hierarchical decisionmaking system and the fuzzy system to design an appropriate distance between vehicles. Michon [85] proposed a cognitive model of driver's decision-making process, which can achieve quantitative measurement and provide three types of decisions: strategic, technical and operational. Yang [86] gave a longitudinal driver model and a lateral driver model to study the mechanism of accident using the optimal control theory. Guo et al. [87] proposed a closed-loop control system of human-vehicle-road and established a driver preview follower model as well as a preview optimal curvature model. The research of driver behavior in China is in its early stage.

\section{Vehicle and road surface interaction}

In 1987, Frybal stated that "the dynamic issues of vehiclepavement interaction is a new branch of the science". Since this research field has emerged dealing with dynamics problems of vehicle, road and the interaction between them [88]. So far, the research field has not been fully developed yet except for a few publications. It is well recognized that the vehicle can cause the damage to the pavement. In 1958 the American association of highway and transportation officials (AASHO) began to focus on the pavement damage caused by the vehicle traveling. Based on many road tests under the different vehicle loadings, AASHO obtained the famous "fourth power law" [89]. The law states that there is a fourth power function relation between the fatigue damage of the pavement and the vehicle static axle load. The fourth power law is important to the design of pavement structure. However, the law doesn't consider the dynamical loading effect of vehicle on the pavement. In the 1970s, West Germany highway department proposed the evaluation of "Road Stress Factor" [90], which took into account the effect of dynamical axle load on the pavement. The evaluation pointes out that the damage is largely caused by the vehicle axle load (including the static axial load and dynamical axle load) and the contact area between the tire and the road surface. Canadian roads and transport association organized a joint commission to research the vehicle quality and size. They studied the interaction between the truck and the pavement or bridge. The purpose is to study the effect of design, size and quality safety limit of the truck on the roads, bridges, security and transport policy [91-93]. In 1987, the United States Congress adopted and launched the Strategic Highway Research Program (SHRP), focusing on the research of four fields: asphalt road, pavement performance, concrete structure and road transportation [94]. In the early 1990s, TRL's transportation institute of the university of Cambridge, UK, studied on interactions between the vehicle and road surface to assess the driving safety, suspension structure design, failure mechanism of asphalt pavement, research and development of dynamical weighing equipment, and so on [95,96]. At the University of California, Beckeley, the damage caused by the tire pressure and the axial load is studied theoretically and experimentally. Kyongsu's research showed that the dynamical tire force is much higher than the static tire force. Both of the theoretical analysis and the experimental 
results proved that the semi-active suspension using double linear disturbance decoupling observer can reduce the tire dynamical force and the damage on the pavement [97]. The European organization for the economic co-operation and development (OECD) put forward the road traffic research project entitled "Dynamic Interaction between Vehicles and Infrastructure Experiment (DIVINE)" [98] and investigated the interaction mechanism of vehicles, pavement and bridge. A total of 19 countries had participated and conducted experiments in the indoor accelerated pavement test facility (CAPTIF) in Canterbury of New Zealand, on the proving ground in Virtta, Finland.

With the modal superposition and integral transformation method, Seong-Min and McCullough [99] studied the dynamical response of plates on the viscous Winkler foundation under the moving loads with varying amplitudes. Huang and Thambiratnam [100] also analyzed the dynamical response of thin plates with the Winkler foundation under the moving point harmonic load. Kim [101], Chen and Huang [102] and many others studied the effects of vehicle parameters on multilayer pavement's dynamics with the finite element method. Mamlouk and Brademeyer [103] proposed a concept of vehicle-pavement interaction, which can be applied to weigh-in-motion, pavement design, and performance and vehicle regulation. Cebon concluded that the interaction of vehicle and road is a weak coupling system for two reasons: (1) the displacement of the pavement is $0-1 \mathrm{~mm}$, much smaller than the deflection of the tire and suspension (10-20mm); (2) the speed of elastic waves in the road profile is $100-600 \mathrm{~m} / \mathrm{s}$, much greater than the vehicle running speed $(10-50 \mathrm{~m} / \mathrm{s})$ [104].

The research on the vehicle-road interaction in China is mainly carried in the universities. As early as 1965, Fang et al. recognized that the vibration of the vehicle is caused by the pavement irregularity [105,106]. Sun and Deng [107] analyzed the influence of vehicle parameters on the dynamic load in detail by using the random theory based on a simplified quarter vehicle model. Lv et al. [108] established a heavy vehicle model for optimization of improved vehicle ride comfort and reduced tire dynamic shock to the ground. Lv' and Dong [20] other achievements are summarized in the monograph entitled "Mechanical Analysis of Vehicle-Asphalt Pavement System". Lu et al. [109] investigated a heavy vehicle-tire-road coupled system and found that nonlinearities in the vehicle suspension contribute to the improved ride comfort and reduced dynamic tire force. Yang et al. [110] developed a 3D car-pavement-subgrade coupled model and studied the effect of vehicle-pavement coupling on the vehicle body acceleration, suspension deformation, tire force and the surface displacement by comparing the dynamical response of this model and the traditional vehicle-road model. A nonlinear vehicle-road coupled system involves a 7 DOF vehicle moving along a simply supported double- (a)

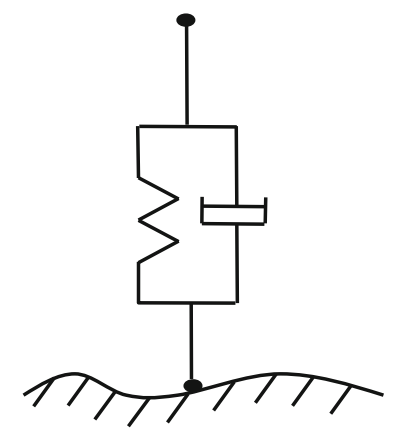

(b)

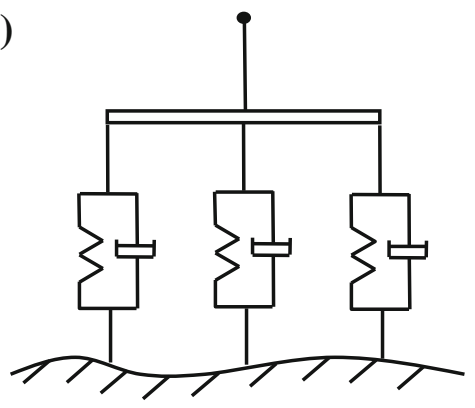

(c)

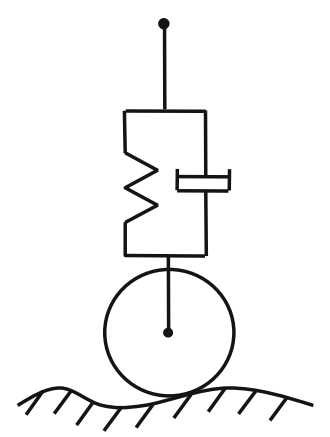

Fig. 4 Contact relationship between tire and road surface, a Single point-contact model [54-57], b Fixed foot print model [60], c Enveloping model (rigid, flexible) [63-65]

layer rectangular thin plate on a nonlinear viscoelastic foundation, as shown in Fig. 4. It is found that the nonlinearity of vehicle and the viscoelasticity of road material should be considered when the vehicle-road system response is studied [111].

Despite of all these studies, the important issues about the interaction between the vehicle and road surface are still not resolved. The contact mechanism between the tire and road surface needs further investigations (Fig. 5).

\section{The prospects of vehicle dynamics research}

Through several decades of development, vehicle dynamics has achieved some success in handling stability, ride comfort and road friendliness. Much further work is needed in the following areas. 
Fig. 5 The nonlinear vehicle-road coupled system

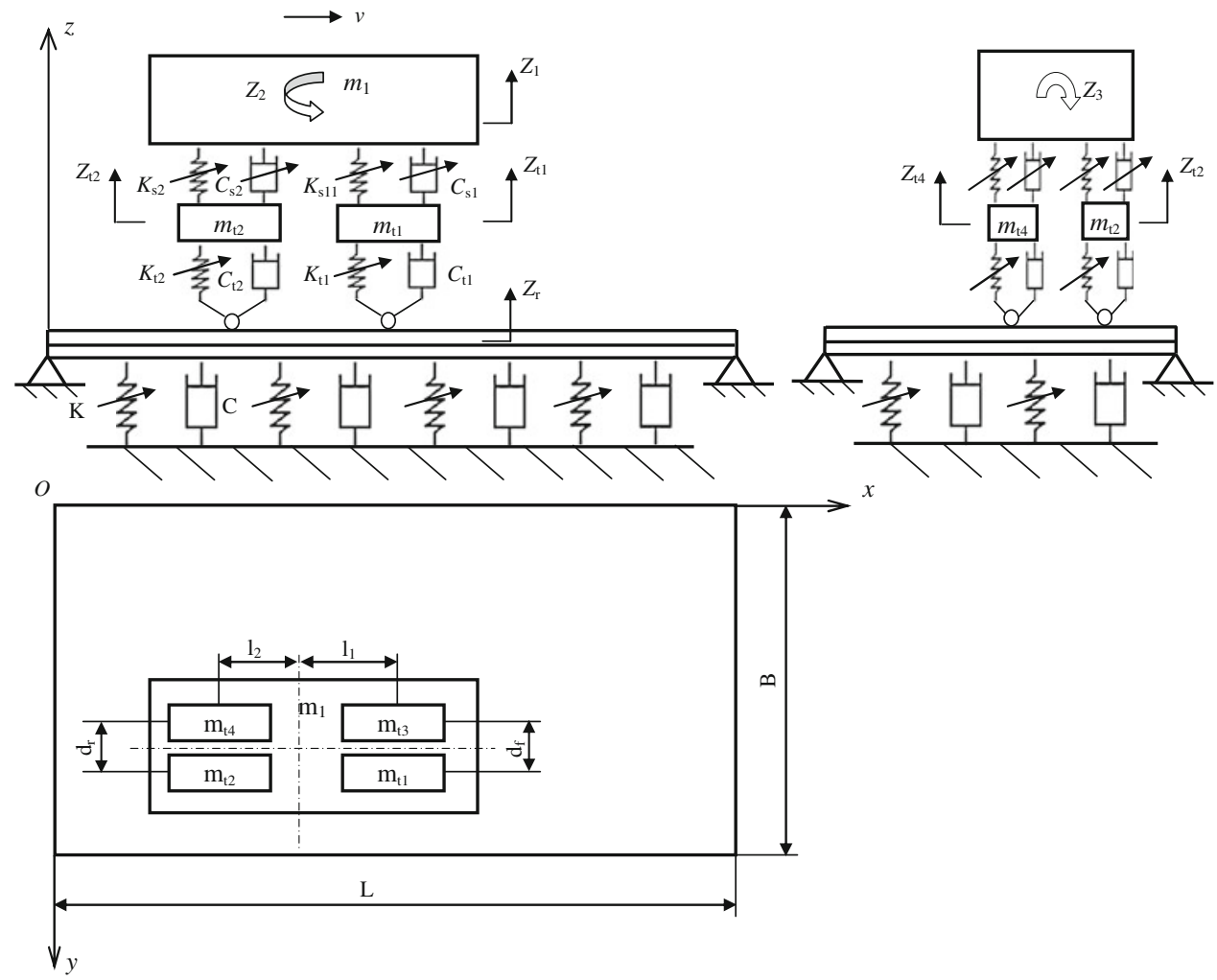

(1) Comprehensive nonlinear dynamic modeling of the vehicle system is needed. When the vehicle is running in transient maneuver, nonlinearities in the vehicle system strongly influence the dynamics and should be considered. Furthermore, nonlinear components of the vehicle introduce complex dynamic phenomena including bifurcations and chaos, which are worth studying.

(2) The secure, intelligent and energy-efficient suspension system is a trend in the automobile industry. The quality actuators, cost-effective and reliable sensors, modern control technology and high performance microprocessors will play significant roles in the intelligent vehicle suspension, and bring about a broad range of research opportunities.

(3) The contact relationship between the tire and road surface is usually modeled by the spring and damping elements, and is simplified as the point contact or line contact. The contact friction coefficient is generally taken to be the static friction without considering the surface physical characteristics and the finite-area dynamical contact. The dynamic mechanical properties of tire rolling contact, the contact mechanism between a tire and the road surface need further investigations.

Acknowledgments This work was supported by the National Basic Research Program of China (2012CB723301), NSFC Key Program (Grant No. 10932006), National Natural Science Foundation of China
(Grant Nos. 11102121, 51208319) and the Natural Science Foundation of Hebei Province (Grant Nos. A2012210018, E2012210025).

\section{References}

1. Manfred MMM (2009) Henning Wallentowitz. Vehicle system dynamics. Tsinghua University Press, Beijing

2. Dave C, Yu F (2004) Vehicle system dynamics and control. China Communications Press, Beijing

3. Segel L (1993) An overview of developments in road vehicle dynamics: past, present and future. In: Proceedings of IMechE conference on vehicle ride and handling, London, pp 1-12

4. Abe M (2009) Vehicle handling dynamics: theory and application. Butterworth Heinemann, Oxford

5. Guo KH (2011) Vehicle handling dynamics theory. Jiangsu Science and Technology Press, Nanjing

6. Rajesh R (2005) Vehicle dynamics and control. Springer-Verlag, New York

7. Zhang LJ, He H (2011) Vehicle dynamics theory and application. National Defense Industry Press, Beijing

8. Yu ZS (2010) Automotive theory, 5th edn. China Machine Press, Beijing

9. Rajesh R (2006) Vehicle dynamics and control. Springer Press, New York

10. Liu YJ, Zhao YQ, Xu JX (2012) Vehicle Handling inverse dynamics based on gauss pseudospectral method while encountering emergency collision avoidance. J Mech Eng 48(22):127-132

11. Kristijan M, Konrad T, Richard G, Roland S (2007) Dynamics modeling and parameter identification for autonomous vehicle Navigation. In: IEEE/RSJ international conference on intelligent robots and systems, pp 3321-3326 
12. Liu XC, Zhang JW, Liu F (2005) A four-wheel-steering nonlinear lateral dynamics model. J Shanghai Jiaotong Univ 39(9):14651469

13. Huh K, Kim J, Hong J (2000) Handling and driving characteristics for six-wheeled vehicles. Proc Inst Mech Eng D 214(2):159

14. Vlk F (1982) Lateral dynamics of commercial vehicle combinations a literature survey. Veh Syst Dyn 11(5, 6):305-324

15. Nagai M, Shino M, Gao F (2002) Study on integrated control of active front steer angle and direct yaw moment. JSAE Rev 23(3):309-315

16. Zhao YQ, Yin H, Zhang LX (2005) Present state and perspectives of vehicle handling inverse dynamics. Chin Mech Eng 16(1):7782

17. Verros G, Natsiavas S, Papadimitriou C (2005) Design optimization of quarter-car models with passive and semi-active suspensions under random road excitation. J Vib Control 11:581-606

18. Parthasarathy SS, Srinivasa YG (2006) Design of an active suspension system for a quarter-car road vehicle model using model reference control. Proc Inst Mech Eng I 220(2):91-108

19. Cao JT, Liu HH, Li P, Brown DJ (2008) An interval type-2 fuzzy logic controller for quarter-vehicle active suspensions. Proc Inst Mech Eng D 222(D8):1361-1373

20. Lv PM, Dong ZH (2010) Mechanical analysis of vehicle-asphalt pavement system. China Communications Press, Beijing

21. Kim C (2002) An accurate full car ride model using model reducing techniques. J Mech Des 124(4):697-705

22. Cebon D (1999) Handbook of vehicle-road interaction. Swets and Zeitlinger, Lisse

23. Lúcio FSP, Becker M, Landre J Jr, Clovis SB (2006) A new vehicle 3D model with 7 degrees of freedom for vehicle dynamical response studies. In: III European conference on computational mechanics solids, structures and coupled problems in engineering, p 773

24. Tan RH, Chen Y, Lu YX (2000) Liner nonlinear modeling and simulation of the ride dynamics for a car. Chin J Mech Eng 36(5): 80-83, 91

25. Gyu HK, Kyu ZC, In BC (2003) Dynamic stress analysis of vehicle frame using a nonlinear finite element method. J Mech Sci Technol 17(10):1450-1457

26. Kuti I (2004) An adaptive fuzzy control to antilock non-straight line braking using three dimensional (finite element) vehicle model. Int J Veh Des 34(4):27-339

27. He YS (1990) Automotive vibration. China Communications Press, Beijing

28. Xiong GL, Guo B, Chen XB (2004) Co-simulation and virtual prototyping technology. Tsinghua University Press, Beijing

29. Valášek M, Novák M, šika Z (1998) Dynamic model of truck for suspension control. Veh Syst Dyn 29(S1):496-505

30. Hou B, Goncalves FD, Sandu C (2004) Dynamic simulation of a full vehicle with magneto-rheological damper. In: Proceeding of ASME IMECE, 6th annual symposium on advanced vehicle technology, Anaheim, pp 767-774

31. Ieluzzi M, Turco P, Montiglio M (2006) Development of a heavy truck semi-active suspension control. Control Eng Pract 14(3):305-312

32. Odhams AMC, Roebuck RL, Cebon D (2008) Dynamic safety of active trailer steering systems. Proc Inst Mech Eng K 22(4):367380

33. Ren WQ, Zhang YQ, Jin GD (2005) Systematic research method for vehicle-road damage. China J Highw Transp 18(4):110-114

34. Yang Y, Ren WQ, Chen LQ (2009) Study on ride comfort of tractor with tandem suspension based on multi-body system dynamics. Appl Math Model 33(1):11-33

35. Lu YJ, Yang SP, Li SH (2010) Numerical and experimental investigation on stochastic dynamic load of a heavy duty vehicle. Appl Math Model 34(10):2698-2710
36. Ren LQ (2009) Experimental design and optimization. Science Press, Beijing

37. Hu GH, Zhu WH, Cai HX (2009) Mathematical model for abrasive suspension jet cutting based on orthogonal test design. J Shanghai Univ 13(1):37-44

38. Snežana P, Ljubomir L (2009) Orthogonal array and virtualization as a method for configuration testing improvement. In: First IEEE Eastern European conference on the engineering of computer based systems, Novi Sad, pp 148-149

39. Lu YJ (2011) Research on dynamics of heavy vehicle and road surface interaction. Beijing Jiaotong University, Beijing

40. Pacejka HB (2006) Tyre and vehicle dynamics. ButterworthHeinemann, Oxford

41. Peng C, Cowell PA, Chisholm CJ, Lines JA (2004) Lateral tyre dynamic characteristics. J Terramchanics 31(6):395-414

42. Gim G, Nikravesh PE (1990) An analytical model of pneumatic tires for vehicle dynamic simulations: part 1. Pure slips. Int J Veh Des 11(6):589-618

43. Gim G, Nikravesh PE (1991) An analytical model of pneumatic tires for vehicle dynamic simulations: part 2. Comprehensive slips. Int J Veh Des 12(1):19-39

44. Li SH, Yang SP, Li HY (2012) Dynamic analysis of pavement under three-directional tire force. J Vib Shock 31(13):31-35

45. Dugoff H, Fancher PS, Segel L (1978) An analysis of tire traction properties and their influence on vehicle dynamic performance. SAE Paper No. 7000377:64-66

46. Guo KH, Lu D (2005) The theoretical and experiment study on tire cornering properties under dynamic vertical load. Automot Eng 27(1):89-92

47. Guo KH, Yuan ZC, Lu D (2006) A study on the prediction capability of UniTire model for combined slips mode. Automot Eng 28(6):565-568

48. Rao KVN, Kumar RK (2007) Simulation of tire dynamic behavior using various finite element techniques. Comput Methods Eng Sci Mech 8(5):363-372

49. Gall R, Tkacik P (1993) On the incorporation of frictional effects on the tire/ground contact area. Tire Sci Technol 21(1):2-22

50. Hadi MNS, Bodhinayake BC (2003) Non-linear finite element analysis of flexible pavements. Adv Eng Softw 34:657-662

51. Cho JR, Kim KW, Jeong HS (2007) Numerical investigation of tire standing wave using 3-D patterned tire model. J Sound Vib 305:795-807

52. Pauwelussen JP, Gootjes L, Schröder C, Köhneb KU, Jansenc S, Schmeitzd A (2003) Full vehicle ABS braking using the SWIFT rigid ring tyre model. Control Eng Pract 11(2):199-207

53. Guan DH, Fan CJ (2004) A review of tire models for vehicle dynamics simulation on uneven road. Automot Eng 26(2):162167

54. Yi K, Wargelin M, Hedrick K (1992) Dynamic tire force control by semi-active suspensions. ASME Winter Annual Meeting, Anaheim, No 97, November

55. Collins RL (1972) Frequency response of tires using the point contact theory. J Aircr 9(6):427-432

56. Arūnas R, Jonas S (2002) The role of a tire in vehicle and road interaction. Transport 17(2):39-45

57. Costanzi M, Cebon D (2007) An investigation of the effects of lorry suspension performance on road maintenance costs. Proc Inst Mech Eng C 221(11):1265-1277

58. Hurtford S (2009) Improving the quality of terrain measurement. Virginia Polytechnic Institute and State University, Danville

59. Lippmann SA, Piccin WA, Baker TP (1965) Enveloping characteristics of truck tires. A Laboratory Evaluation, SAE650184

60. Captain KM, Boghani AB, Wormley DN (1979) Analytical tire models for dynamics vehicle simulation. Veh Syst Dyn 8(1): $1-32$ 
61. Guo KH, Liu Q, Ding GF (1998) Influences of loading and inflation pressure on tire enveloping properties. Trans CSAE 14(3):5355

62. Guo KH, Liu Q, Ding GF (1999) Analysis of tire enveloping properties and its application in modeling of vehicle vibration systems. Automot Eng 21(2):65-71, 80

63. Guo KH (1993) Tire roller contact model for simulation of vehicle vibration input. Soc Automot Eng (SAE 932008) 991:45-51

64. Guan X, Dong B (2003) An active suspension system with enveloping tire model. Automot Eng 25(4):356-359

65. Zegelaar PWA (1998) The dynamic tyre response to brake torque variations and road unevennesses. Delft University of Technology, Delft

66. Guo KH (1991) Vehicle handling dynamics. Jilin Science and Technology Press, Changchun

67. Yang SP, Li SH, Lu YJ (2009) Dynamics of vehicle-pavement coupled system based on a revised flexible roller contact tire model. Sci China Ser E 52(3):721-730

68. Beer De M, Sadzik EM (2007) Comparison of contact stresses of the test tyres used by the $1 / 3 \mathrm{RD}$ scale model mobile load simulator (MMLS3) and the full-scale test tyres of the heavy vehicle simulator (HVS) a summary. In: Proceedings of the 26th Southern African transport conference, Pretoria

69. Beer De M, Sadzik EM, Fisher C et al (2005) Tyre-pavement contact stress patterns from the test tyres of the Gautrans heavy vehicle simulator. In: Proceedings of the 24th Southern African transport conference, Pretoria

70. De Beer M (1996) Measurement of tyre/pavement interface stresses under moving wheel loads. Heavy Veh Syst 3(1-4):97115

71. Groenendijk J, Miradi A, Molenaar AAA (1997) Pavement performance modeling using LINTRACK. In: Proceeding 8th international conference on asphalt pavements, pp 1505-1526

72. Ronald B (1999) Introducing improved loading assumptions into analytical pavement models based on measured contact stresses of tires. In: International conference on accelerated pavement testing, Reno

73. Hu XD, Sun LJ (2006) Stress response analysis of asphalt pavement under measured tire ground pressure of heavy vehicle. $\mathrm{J}$ Tongji Univ (Nat Sci) 34(1):64-68

74. Hu XD, Sun LJ (2005) Measuring tire ground pressure distribution of heavy vehicle. J Tongji Univ (Nat Sci) 33(11):14431448

75. Neves RRV, Micheli GB, Alves M (2010) An experimental and numerical investigation on tyre impact. Int J Impact Eng 37(6): 685-693

76. Gibson JJ, Crooks LE (1938) A theoretical field-analysis of automobile-driving. Am J Psychol 11(3):453-471

77. McRuer D (1980) Human dynamics in man-machine systems. J IFAC 16:237-253

78. MacAdam CC (2003) Understanding and modeling the human driver. Veh Syst Dyn 40(1-3):101-134

79. Kiencke U, Nielsen L (2000) Automotive control systems: for engine, driveline, and vehicle. Springer-Verlag, Berlin

80. Thomas AR (1994) Models of driving behavior: a review of their evolution. Accid Anal Prev 26(6):733-750

81. Cacciabue PC (2007) Modelling driver behavior in automotive environments (HRD). Springer-Verlag, New York

82. Baron S, Kleinman DL, Levison WH (1970) An optimal control Model of human response part I, II. Automatica 6:357-383

83. Torsten B, Oskar VS (2005) Optimal control based modeling of vehicle driver properties. SAE 2005 World Congress and Exhibition, Paper Number 2005-01-0420

84. Cheng B, Fujioka T (1998) Driver model by fuzzy logic for merging. Trans Jpn Soc Mech Eng 64(628):4745-4750
85. Michon JA (2001) A critical view of driver behavior models: what do we know, what should we do? Human behavior and traffic safety. Plenum Press, New York

86. Yang HH (2010) Driver models to emulate human anomalous behaviors leading to vehicle lateral and longitudinal Accidents. $\mathrm{PhD}$ Dissertation, University of Michigan

87. Guo KH, Ma FJ, Kong FS (2002) Driver model parameter identification of the driver-vehicle-road closed-loop system. Automot Eng 24(1):20-24

88. Fryba L (1999) Vibration of solids and structures under moving loads. Thomas Telford Ltd., London

89. Association American of State Highway and Transportation Officials (1962) The AASHO road test, Report 7. Summary Report, Highway Research Board, Report $61 \mathrm{G}$

90. Yu ZP, Huang XP, Zhang HX (1994) The alleviation of damage to road by heavy vehicle-optimization design of vehicle-suspension. China J Highw Transp 7(3):83-87

91. Joseph FS (2003) Heavy truck weight and dimension limits in Canada. The Railway Association of Canada, Ottawa

92. Transportation Association of Canada (1999) Geometric design guide for Canadian roads. Transportation Association of Canada, Ottawa

93. Furtado G, Easa SM, Abd El Halim AO (2002) Vehicle stability on combined horizontal and vertical alignments. In: Annual conference of the Canadian society for civil engineering, Montréal

94. Jorge BS, Joseph C, Carl LM (1991) Summary report on permanent deformation in asphalt concrete. Transportation Research Board Business Office, Washington

95. Cebon D (1990) Design of multiple-sensor weigh-in-motion systems. Proc Inst Mech Eng 204(2):133-144

96. Cebon D (1996) Heavy vehicle vibration - a case study. Proc Inst Mech Eng 15(S1):30-43

97. Yi K, Hedrick J K (1989) Active and semi-active heavy truck suspensions to reduce pavement damage. Society of Automotive Engineers, paper no 892486

98. OECD DIVNE (1998) Dynamic interaction between vehicles and infrastructure experiment: technical report. Organization for Economic Co-operation and Development (OECD), Road Transport Research, Scientific Expert Group, Paris

99. Seong-Min K, McCullough BF (2003) Dynamic response of plate on viscous Winkler foundation to moving loads of varying amplitude. Eng Struct 25:1179-1188

100. Huang MH, Thambiratnam DP (2002) Dynamic response of plates on elastic foundation to moving loads. J Eng Mech 128(9):10161022

101. Daehyeon K, Rodrigo S, Adolph GA (2005) Effects of supersingle tire loadings on pavements. J Transp Eng ASCE 131:732-743

102. Chen FF, Huang XM (2007) Analysis of the mechanical response of rigid base asphalt pavement under heavy load. J Highw Transp Res Dev 24(6):41-45

103. Markow MJ, Brademeyer BD (1996) Analyzing the interactions between dynamic vehicle loads and highway pavement. Transp Res Rec 1196:161-169

104. Cebon D (1985) An investigation of the dynamic interaction between wheeled vehicles and road surfaces. PhD Dissertation, University of Cambridge

105. Deng XJ, Sun L (2000) Study on dynamics of vehicle-ground pavement structure system. China Communications Press, Beijing

106. Deng XJ (2002) Study on dynamics of vehicle-ground pavement structure system. J Southeast Univ (Nat Sci Ed) 32(3):474-479

107. Sun L, Deng XJ (1996) Mathematic model and experiment design of dynamic load. J Xi'an Highw Univ 16(4):50-53

108. Lv PM, He LM, Y JM (2007) Optimization of vehicle suspension parameters based on comfort and tyre dynamic load. China J Highw Transp 20(1):112-117 
109. Lu YJ, Yang SP, Li SH (2011) Research on dynamics of a class of heavy vehicle-tire-road coupling system. Sci China Technol Sci 54(8):2054-2063

110. Yang SP, Li SH, Lu YJ (2010) Investigation on dynamical interaction between a heavy vehicle and road pavement. Veh Syst Dyn 48(8):923-944
111. Li SH, Yang SP, Chen LQ et al (2012) Effects of parameters on dynamic responses for a heavy vehicle-pavement-foundation coupled system. Int J Heavy Veh Syst 19(2):207-224 